\title{
O SIGNIFICADO DE CASA E RUA PARA MENINOS COM EXPERIÊNCIA DE VIDA NAS RUAS: EM BUSCA DE UMA COMPREENSÃO SOBRE AS IMPLICAÇOES PARA A SAUDE
}

\author{
THE MEANING OF HOUSE AND STREET FOR BOYS WITH \\ EXPERTENCE OF LIFE IN THE STREETS: SEARCHING FOR AN \\ UNDERSTANDING Of HEALTH IMPLICATIONS
}

\author{
Marcelo .Medeiros ${ }^{1}$ \\ Maria das Graçus Carvalho Ferriani ${ }^{2}$ \\ Romeu Gomes ${ }^{3}$ \\ Denize Boteleti Munari ${ }^{4}$
}

MEDEIROS, M.; FERRIANI, M. d. G. C.; GOMES, R.; MUNARI, D. B. O significado de casa e rua para meninos com experiência de vida nas ruas: em busca de uma compreensão sobre as implicações para a saúde. Rev. Bras. Cresc. Desenv Hum., São Paulo, 12(2), 2002.

Resumo: O presente trabalho teve como objetivo analisar as representações sociais acerca de casa e rua para meninos com experiência de vida na rua. A pesquisa foi desenvolvida à luz da abordagem social de pesquisa qualitativa em saúde utilizando-se, enquanto princípio metodológico, um recorte das representações sociais das falas de um grupo de meninos abrigados em uma instituição pública. Os resultados, analisados com base na análise de conteúdo - modalidade temática, mostraram que as representações sobre casa e rua se constróem com base em elementos contraditórios. A casa, representada pelo abrigo, supre em parte os vínculos familiares e a rua, apresenta-se enquanto um espaço de liberdade e ao mesmo tempo de privação. Concluindo apontamos que pensar ações em saúde para atender meninos e meninas que vivem e/ou trabalham na rua é uma tarefa bastante complexa, pois não é possível pensarmos em ações isoladas de saúde sendo necessário a busca por parcerias com diferentes instituições.

Palavras-chave: crianças de rua; pesquisa social; saúde pública.

\section{INTROD UÇÃO}

A pobreza extrema de segmentos da sociedade brasileira tem contribuído para a situação de abandono da infância e da juventude que permanece nas ruas das grandes cidades do país, pedindo esmolas, comida, vigiando carros em troca de algum dinheiro, vendendo balas e doces nos semáforos, roubando, envolvendo-se com drogas e sendo explorada por adultos sem escrúpulos. De acordo com PRADO e GOMES (1993), aliada aos conflitos familiares, a pobreza torna-se o principal fator que os impulsiona às ruas em busca de geração de renda, seja por meios socialmente aceitos ou não.

As estatísticas apontam um grande contingente de crianças e adolescentes nas ruas, onde predomina o sexo masculino, envolvidos em algum tipo de trabalho durante o periodo diurno. $\mathrm{O}$ número daqueles que permanecem nas ruas durante a noite perambulando e dormindo é mais significativo do que o daqueles que estão traba-

1 Doutor em Enfermagem, Professor Adjunto da Faculdade de Enfermagem da Universidade Federal de Goiás. Rua 227, Qd 68 s/n - FEN; Setor Leste Universitário; CEP 74605-^s00, Goiania, Goiás. E-mail: marcelo@fen.ufg.br.

2 Doutora em Enfermagem, Professora Titular do Departamento de Enfermagem Matenno-Infantil e Saúde Púhlica da Escola de Enfermagem de Ribeirão Preto da USP. E-mail: caroline@glete.cerp.usp.br.

3 Doutor em Saúde Pública, Professor e Pesquisador Associado do instituto Fernandes Figueira / FIOCRUZ. E-Mail: romeu@iff.fiocruz.br.

4 Doutora em Enfermagem, Professora Titular da Faculdade de Enfermagem da Universidade Federal de Goiás. E-mail: denize@fen.ufg.br. 
lhando (ABRINQ e col., 1994; MEDEIROS \& FERRIANI, 1995; MEDEIROS, (1999). SOUZA e PEREIRA (1995) complementam este perfil apontando que grande parte das crianças é negra, entre 6 e 18 anos de idade e possui nível de escolaridade muito baixo. Recentes estudos (GOIÂNIA, 2002) revelam que, em Goiânia, assim como em outras capitais brasileiras, as características se repetem, acrescentando que a idade gira em torno dos 7 a 17 anos, com concentração na faixa de 11 a 14 anos, cujas famílias migrantes vivem em bairros periféricos da capital com renda familiar entre 1 e 5 salários mínimos. Este último fator contribui essencialmente para que os adolescentes busquem no mercado informal de trabalho da rua uma alternativa para contribuir na renda familiar.

MINAYO (1993b) e MEDEIROS (1999) apontam que a maioria dos meninos em situação de rua constitui-se de meninos trabalhadores, que desenvolvem atividades geradoras de renda ligadas à economia formal ou informal, mas o grupo considerado especificamente como 'menino de rua' com ou sem vinculo familiar, vive e mora pelas ruas. A força das circunstâncias, porém, pode fazer com que estes meninos e meninas estejam por vezes nas delegacias, albergues, casas abrigos, instituições de caridade ou, ainda, em lares substitutos.

Tomando como ponto de partida estes aspectos contextuais, propomos para este artigo uma leitura com base nas seguintes categorias de análise: “Casa-Rua" e "Violência”. Na primeira, entendemos estar implícita a questão do espaço público, considerando seus locais abertos tais como praças, ruas, avenidas, parques, jardins, entre outros e, ao mesmo tempo, do espaço privado constituído pelas casas ou lares onde o convívio é, de certa fonna, restrito aos membros de uma família. Devemos considerar que existe ainda espaço limítrofe entre a casa e a rua, isto é, aquele em, que embora o acesso público seja permitido, possui regras e caráter transitório tais como escolas, unidades de saúde, igrejas, clubes, albergues, entre outras instituições. Para a discussão sobre estes aspectos, encontramos importantes elementos complementares em DA MATTA (1997), FENELON e cols. (1992) e BOUDON e BAURRICAUD (1993).

Segundo DA MATTA (1997), “casa” e "rua” são categorias sociológicos no sentido de um código de valores e idéias. Para as pessoas que habitam a rua, a necessidade de delimitar um espaço privado semelhante ao da casa é muito forte. CRUZ NETO (1993) observa que a transformação e o aproveitamento de locais na rua em casas são evidenciados a partir do momento em que terrenos, casas e escolas abandonadas, vãos sob pontes ou viadutos e marquises são invadidos e delimitados com papelão, plástico e madeira. Assim, improvisam suas casas delimitando no espaço público da rua, seus espaços privados.

Na segunda categoria, "violência”, observamos que se trata de um tema controverso e sujeito a uma compreensão interdisciplinar. Entendemos que a violência possui caráter histórico e social que, de acordo com a cultura de diferentes sociedades e o grau de desenvolvimento destas, assume diferentes definições, características, conteúdos e estratégias para sua prática, embora alguns aspectos sejam comuns.

Em termos conceituais, compartilhamos com MINAYO (1994) que a violência não se restrrnge ao mundo da delinquência e, de um modo bastante geral, pode ser classificada em violência estrutural (entendida como aquela que se refere às desigualdades sociais que levam à opressão e à discriminação de grupos vulneráveis), de resistência (que se constitui das diferentes formas de resposta dos grupos, classes e indivíduos oprimidos) e da delinqüência (que se revela nas ações fora da lei socialmente reconhecida).

Segundo GOMES (1996), viver na rua implica a negação de condições mínimas para uma vida de qualidade. Para esse autor, "o sistema estruturalmente violento, além de não permitir o acesso de pessoas aos padrões adequados à vida, decreta a morte destas pessoas previamente excluídas” (p. 253).

A partir dessas considerações, neste artigo objetivamos analisar as representações sociais acerca de casa e rua para meninos com experiência de vida nestes espaços, à luz das categorias de análise apresentadas, e que se encontram abrigados em instituição específica para acolher esta população, com vistas a discutir as implicações de tais significados nas ações de saúde.

\section{PRINCÍPIOS METODOLÓGICOS}

Desenvolvemos esta pesquisa à luz de uma abordagem social de pesquisa qualitativa em saúde, que se propõe a uma compreensão particular e profunda dos fenômenos onde o pesquisador deve participar, compreender e interpretar os eventos sociais de sua pesquisa, considerando o sujeito de estudo, gente, em determinada condição social, pertencente a um determinado grupo ou classe social com suas crenças, valores e significados sendo o objeto um dado que possui significados e relações que sujeitos concretos criam em suas ações (CHIZOTTI, 1991; HAGUETTE, 1992; MINAYO, 1993a; MINAYO, 2000). 
Em termos de princípios metodológicos optamos por recortar as representações sociais das falas dos meninos que tiveram experiência de vida na rua e das nossas observações de campo. As representações sociais aqui estão sendo compreendidas como "categorias de pensamento, de ação e de sentimento que expressam a realidade, explicam-na, justificando-a ou questionando-a enquanto material de estudo. Essas percepções são consideradas consensualmente importantes, atravessando a história e as mais diferentes correntes de pensamento sobre o social” (MINAYO, 1993a, p. 158). Consideramos que uma representação social "permite em princípio compreender por que alguns problemas sobressaem numa sociedade e esclarecer alguns aspectos de sua apropriação pela sociedade, como os debates e os conflitos que se desenrolam entre diferentes grupos de atores?” (HERZLICH, 1991, p. 27-28).

\section{CAMPO E PERCURSO DO ESTUDO}

Procuramos pelos meninos e meninas em situação de rua na cidade de Goiânia, Capital do estado de Goiás, em um espaço onde estivessem em situação de abrigo. Em um primeiro momento buscamos identificar os programas assistenciais existentes na cidade e, posterioimente, optar por um deles após a devida autorização para utilizar aquele espaço enquanto campo de pesquisa. Obtivemos, em conformidade com a Portaria 196/96 do Conselho Nacional de Saúde, a aprovação do projeto pela Comissão de Pesquisa da Faculdade de Enfermagem da Universidade Federal de Goiás e o consentimento dos coordenadores da Casa Abrigo para coletarmos os dados, uma vez que estes constituem os responsáveis legais pelos meninos ali abrigados.

Como valores sociais desta investigação, optamos por um grupo de adolescentes que tiveram ou ainda têm experiências de vida na rua, em número suficiente para garantir certa reincidência das informações contidas nas entrevistas e, que no conjunto, fossem diversificados no sentido de podermos apreender as semelhanças e as diferenças em suas falas. Procuramos respeitar os critérios básicos para a delimitação da amostragein em pesquisa qualitativa propostos por MINAYO (1993a) que, em síntese, coloca que a amostra ideal é aquela capaz de refletir a totalidade do problema investigado em suas múltiplas dimensões.

Neste trabalho elegemos as técnicas da entrevista semi-estruturada e a observação participante com registro das observações através dc um diário de campo, de maneira que fossem com- plementares entre si. Obtivemos assim dois corpi de análise que foram posteriormente confrontados no sentido de detectarmos as contradições e conflitos existentes, procurando delinear as representações sobre a casa e a rua pelos adolescentes. As entrevistas foram analisadas, juntamente com as anotações do diário de campo, tomando por base a Técnica de Análise de Conteúdo, modalidade Temática. A técnica de análise temática "consiste em descobrir os 'núcleos de sentido' que compõem a comunicacão e cuja presença, ou frequência de aparição, podem significar alguma coisa para o objetivo analítico escolhido" (BARDIN, 1979, p. 105 ), além de buscar respostas para questões. Com esta técnica pode-se caminhar na direção da "descoberta do que está por trás dos conteúdos manifestos indo além das aparências do que está sendo analisado" (GOMES, 2000, p.74).

\section{RESULTADOS E DISCUSSÃO}

\section{A CASA...}

Optamos enquanto espaço de pesquisa por uma Casa Abrigo inserida em um projeto governamental específico de atendimento a crianças e adolescentes em situação de rua. Esta propiciava atendimento sócio educativo garantindo a satisfação das necessidades básicas de moradia, alimentação, vestuário, saúde, escolarização, esporte, cultura e lazer, além de participação em atividades de iniciação à profissionalização para o grupo ali abrigado.

A Casa Abrigo possuía três quartos coletivos e, em cada um deles, duas camas tipo beliche e outra comum, banheiro com vaso sanitário, chuveiro elétrico e pia; sala de dois ambientes com televisor preto e branco, cadeiras, mesa ampla para doze lugares; cozinha equipada com fogão a gás e utensílios suficientes para preparo de pequenas refeições, uma vez que o almoço e o jantar eram oferecidos em outro espaço de outra instituição governamental distante cerca de 100 metros; área de serviço extenna com tanque comum e outro elétrico; além de sala com banheiro destinada à administração.

A dinâmica de funcionamento da Casa era bastante rígida pois, embora os meninos tivessem liberdade para entrar e sair, havia um acordo quanto ao horário para retorno à casa que devia ser rigorosamente observado. Da mesma forma, ao saírem, deviam intònnar o local onde pretendiam ir e com quem estariam. Qualquer deslize significava repreensão verbal e suspensão do "direito" de entrar e sair da Casa por um período determi- 
nado. Envolvimento com drogas, brigas dentro e/ ou fora da Casa poderia consistir forte motivo para o desligamento do menino da Casa, principalmente na reincidência sendo encaminhado novamente à instituição que solicitou o abrigo.

Os meninos chegavam à Casa sob cncaminhamento do Ministério Público, do "SOS Criança” (Programa Municipal de suporte à infância e juventude) ou do Conselho Tutelar. A rotina dos meninos consistia basicamente em um período na escola e outro no trabalho para aqueles que tinham algum vínculo einpregatício formal. Grande parte do tempo permaneciam ociosos, assistindo à televisão, dormindo ou perambulando nas iinediações.

O motivo comum do encaminhamento dos meninos por estas Instituições à Casa Abrigo era a ausência da família e a pennanência destes nas ruas onde estavam se envolvendo com drogas, roubos, furtos, ou outras atividades ilícitas. É importante apontar que os ineninos somente eram encaminhados a partir do momento que existisse o interesse do próprio em sua recuperação, devido ao caráter da Casa de não privação de liberdade. Caso contrário, os educadores continuavam o trabalho de abordagem e acompanhamento pelas ruas no sentido de alertá-los quanto às implicações e riscos de viverem nas ruas.

Quanto aos educadores, durante a etapa do trabalho de campo, foi possível percebermos que mantinham relacionamento com base no respeito mútuo, cordialidade e amizade com os meninos e vice-versa. Eles expressavam uma preocupação de fortalecer vínculos, no sentido de resgatar um pouco da falta da convivência familiar. Cada um deles contribuía com o que lhe era possível, às vezes extrapolando seus limites mas as ações, de um modo geral, baseavarn-se em iniciativas individuais, isoladas e sem estarem alicerçadas em projeto pedagógico sistematizado proposto pelo órgão governamental responsável pela Casa Abrigo. Reconheciam o fato de que o trabalho realizado era superficial, embora demonstrassem muita dedicação em criar alternativas para driblar a falta de vontade política e de recursos para atender aos meninos de modo mais próximo ao adequado.

A partir de nossas observações inferimos que, simbolicamente, os adultos educadores representavam as famílias dos meninos, $\mathrm{t}$ 'azendo com que os adolescentes, mesmo estando nas ruas em espaços abertos e gozando de uma relativa liberdade, preservassem o vínculo existente com a Casa. Este aspecto ref' orça a questão da importância do ambiente para o menino onde os educadores assumem a posição ou desempenham o papel de sua família. A manutenção ou resgate dos vínculos afetivos é uma tarefa básica para o educador que tra- balha com meninos que já saíram das ruas, de modo a proporcionar oportunidades que os levem a aprender e pensar com a própria experiência, com vistas a resgatar a confiança em sua capacidade enenfrentar os desafios que certamente encontrarão durante o processo de reintegração.

Durante o período de coleta de dados oito adolescentes do sexo masculino habitavam a Casa Abrigo, em média há seis meses e a idade girava em torno de 14 a 16 anos. Todos tiveram experiência de vida nas ruas de Goiânia no mínimo por seis meses chegando até a vários anos. De um modo geral, a relatividade de meninos na Casa Abrigo sempre fora muito grande, embora no período não observamos evasão e/ou inclusão de novos meninos. Cada um dos meninos entrevistados possuia uma história de vida distinta e peculiar, oriundos de famílias pobres, sendo que algumas delas ainda vivem em bairros periféricos da cidade de Goiânia e no interior dos Estados de Goiás e do Pará. A violência, a violação dos seus direitos e a pobreza foi constante em suas falas, permeando momentos importantes nos relatos da vida de cada um.

Observamos que os vínculos familiares apresentam-se enfraquecidos, rompidos ou, ainda, inexistentes. Mais especificamente, entre os oito meninos, um fora abandonado quando criança e não sabe do paradeiro de sua família. Quatro deles, embora saibam onde é possível encontrar algum membro da família, não possuem nenhum vínculo com estes; um dos meninos mantém vínculo familiar enfraquecido pela distância que se encontram seus pais pois vivem no interior do Estado do Pará. Outro menino, devido à morte dos pais, rompera os vínculos com os familiares mas, eventuahnente o avô paterno o procura na própria Casa Abrigo. Encontramos apenas um menino que mantinha contatos regulares com sua mãe e irmãs, as quais visitava periodicamente nos finais de semana, conforme infonmava.

O grupo de meninos em questão pareceunos bastante integrado havendo um clima de amizade e solidariedade entre eles, embora eventualmente surgissem desentendimentos. Era bastante comum observarmos cenas de ajuda mútua e de compartilhamento; por exemplo, sc um calçado fosse doado a um deles e este não lhe servisse, certamente o doava a algum colega da própria Casa. Porém, presenciamos eventuais desentendimentos entre eles, sem maiores conseqüências entre os envolvidos.

Segundo SILVA (1993), a convivência entre meninos e meninas em situação de rua expressa uma solidariedade que surge a partir de problemas concretos e comuns vivenciados por eles mas, ao mesmo tempo, conflitos ou desconfiança 
aparecem em relação aos colegas do grupo no qual está inserido ou até mesmo com outros grupos. No entanto, ainda segundo este autor, em determinadas circunstâncias, a necessidade individual se sobrepõe à do grupo o que leva geralmente a uma ruptura das regras existentes em benefício da própria sobrevivência.

Neste sentido, apreendemos que a Casa Abrigo, juntamente com os profissionais que ali trabalham e os outros meninos, assume uma referência que traduz o significado de uma casa para este grupo de meninos. Dizemos isso com base em nossas observações de que naquele espaço desenvolviam suas relações com pessoas externas à família original mas que, de uma forma ou outra, representam o seu grupo familiar. No entanto, não podemos dizer que os vínculos estejam suficientemente fortalecidos para que haja uma reintegração à sociedade, pois isto requer um trabalho intensivo por parte dos profissionais que trabalham com meninos e meninas com história de vida na rua para localizar a família do meni-no(a). Uma vez encontrada a família, um trabalho que busque a reintegração do menino à própria família deve ser promovido com vistas a oferecer o suporte necessário para que possam encontrar caminhos viáveis para garantir que esta reintegração aconteça de fato.

\section{... E A RUA}

De um modo geral, apreendemos na leitura do material coletado junto aos meninos, mais precisamente através das entrevistas, que as representações sobre a rua se constróem a partir de elementos bastante contraditórios. Embora sejam elaboradas basicamente por aspectos negativos como a humilhação, falta de casa, comida e carinho, aspectos ligados à liberdade encontrada nas ruas, a possibilidade de fazer o que quiserem sem prestar satisfações a ninguém e também de se divertirem, estão presentes e são marcantes em suas falas. A seguir discutimos estes aspectos através dos núcleos de sentido inerentes à rua identificados nas falas dos meninos.

\section{A) espaço de liberdade}

De um modo geral, as falas dos meninos sugerem momentos de diversão, mostrando que, para eles, o importante da rua é o que existe de corriqueiro e efêmero trazendo as representações da liberdade. Assim, a rua enquanto um espaço de liberdade traz um significado onde está implí- cito: a ausência de normas, o uso de drogas e a participação em pequenos furtos:

"O que eu gostava mesmo é que era sem norma, a gente fazia hagunça demais “ $(E-$ 8 ).

“... no começo eu cheirava cola, depois eu comecei a fumar maconha e, só droga pesada depois... eu gostava disso (E 5).

"Eu gostava... gostava de roubar.. de se divertir; né? (E-1).

Desde o final da década passada o consumo de drogas no Brasil tem sido uma preocupação constante considerando o crescente aumento do número de usuários, na maioria crianças e adolescentes. Alguns estudos têm sido direcionados ao consumo de solventes, entre outras drogas, pelos meninos e meninas em situação de rua. $\mathrm{O}$ solvente mais comum apontado por CARLINI COTRIM e CARLINI (1987a; 1987b) e consumido por este grupo é a cola de sapateiro e entre as outras drogas destacam-se a maconha, ansio-líticos entre outras.

O sexo e a transa enquanto algo prazeroso não estão presentes em todas as falas mas quando aparecem podemos perceber que traduzem outro significado das representações de liberdade que a rua oferece. Segundo MEDEIROS et al. (2001), para um grupo de meninos em situação de rua na cidade de Goiânia, a sexualidade restringe-se ao ato sexual, o qual é prazeroso e vários espaços da rua são utilizados para sua prática. Estes autores também afirmam que, embora não seja uma constante, a homossexualidade e a prostituição perpassam o universo do grupo.

FENELON e cols. (1992) observou junto a um grupo de "meninos e meninas de rua”, também da cidade de Goiânia, que as manifestações afetivas entre eles são pouco comuns e geralmente os tratamentos dispensados são ríspidos e até agressivos. Geralmente as meninas, sonham com um grande amor que será capaz de mudar suas vidas e, quando estão envolvidas com algum menino, vivem intensamente aquela experiência. Os meninos também, segundo as autoras, almejam uma relação afetiva sólida como o casamento mas a escolha da futura noiva incidirá entre aquelas que não estão nas ruas, pois estas são para casar e as que estão nas ruas não servem para o casamento.

\section{B) espaço de privação}

Conforme a fala dos meninos entrevistados, a rua é um lugar cujas representações tam- 
bém se fundamentam naquilo que sentem falta, “não tem nada de bom” pois ali não encontram um espaço fixo para permanecerem ou um lugar para ficarem aquecidos nos dias de frio, onde não têm famIlia, o carinho dos pais, a mãe:

"Falta de carinho dos pais né... assim, sentia saudade né... “ (E-I).

“De boa assim eu acho que não tem nada não, só tem... tem mas não tem. A gente passa num lugar ... acaba passando um frio danado, ai a gente pede assim uma comida para uma pessoa " (E-2).

Também referem não ter amigos e segun do um deles na rua se tem apenas colegas:

"A gente não tem amigo., a gente tem colegas. A gente não tem .so.ssego nem pré dormir, eles tentam matar a gente dormindo" (E-3).

Quanto às roupas, comida e dinheiro, improvisam soluções para sua falta:

"Quando eu não tinha dinheiro encontrava um colega meu que linha né, ai eles faziam, amigo, porque na rua é assim, entendeu, a gente, quando a gente não tem e o outro tem, um dá o socorro para o outro, entende, qualquer coisa ou droga ou a qualquer coisa que tiver" (E-4).

A rua é um espaço sem escola, sem normas, sem futuro. A rua é para quem não tem outra opção mas, ao mesmo tempo, um lugar que se parece com uma casa para quem não tem casa e nenhum lugar para ficar. Uma das entrevistas apontou que, uma vez na rua, eles não têm chance de dela sair e que "tem que existir um mundo melhor".

Observamos que nas falas está implícito que para os meninos a falta dos pais, da proteção do lar, a falta de dinheiro e da escola os leva a cometer atos extremos como roubat para sobreviver. Nesse sentido identificamos que a família para os meninos é algo importante e necessário embora não tenham consciência disso. Este aspecto vem ao encontro das colocações de MELLO (1994) quando aponta que o grupo familiar é a resposta mais satisfatória e essencial para a criação de seus filhos. No entanto, segundo MINAYO (1993b, p. 13): "a família, cuja função cultural é ser a criadora e reprodutora das relações primárias, é aqui ferida no seu cerne quando, por complexas razões econôinicas e sociais, ve-se compelida a ex- pulsar seus filhos para a rua ou aceitar que a utilizem como lugar de vida e trabalho.”

CRUZ NETO (1993), ao estudar famílias de crianças que - em ineio à miséria à qual estão submetidas - buscam na rua a sua sobrevivência, aponta que existe muito sofrimento no trabalho dos pais e das crianças na rua. Neste estudo, os autores observam que o êxodo rural e a migração para a Região Centro-Oeste, em virtude de projetos de interiorização no início desta década, muito contribuíram para o crescimento desordenado de grandes cidades.

Em Goiânia, como em outras grandes cidades brasileiras, é bastante complicado o desenvolvimento urbano acompanhar o fluxo migratório e atender a população que chega em busca de trabalho e melhores condições de vida pois, os migrantes, ao chegarem na capital, encontram dificuldades de acesso a trabalho, escola para seus filhos, habitação, entre outros e, na maioria das vezes se sujeitam a viver em construções improvisadas em terrenos invadidos, pedir esmolas ou ainda viver na rua com toda a família. Segundo CRUZ NETO (1993), estas famílias são vítimas de um processo de exclusão pois não encontram no campo ou na cidade condições mínimas de trabalho, de moradia e de reprodução. Dessa maneira o fenômeno dos "meninos de rua" deve ser explicado mais pelas relações sociais de produção do que pela incursão no urbano de famílias de origem rural.

SARTI (1995) observa que a rua, com seus atrativos de aventura, torna-se um lugar desejável e pode representar para o menino a possibilidade de acesso aos benefícios que a cidade oferece. No entanto, SILVA (1993) destaca que se pode errar ao pensar que a rua funciona prioritariamente como um centro de atração e sonho ou como um local para ganhar dinheiro fácil e sem esforço. Nesse sentido, há que se tomar cuidado para não tomarmos esta questão como fator exclusivo que leva meninos e meninas a procurar a rua, mas a atratividade merece ser vista com cuidado e atenção pois certamente muito contribui para tal.

Entendemos que estes aspectos trazem em essência as representações sociais da necessidade. BOUDON e BOURRICAUD (1993) afirmam que existe uma gênese social das necessidades e discutem esta questão a partir do aspecto das necessidades sociais. Segundo os autores, estas podem ser definidas como a afirmação ou a reivindicação de nossos direitos de sermos reconhecidos, amados e de participação. Em nossa leitura, a necessidade de consumo, seja de gêneros básicos de sobrevivência ou desnecessários ou supérfluos, insere-se no quadro de necessidades sociais. A posse de alimentos para saciar a fome, prover abrigo ou mesmo um parceiro(a), é fonte 
de prazer e satisfação sendo que a privação pode vir acompanhada de condutas de agressão contra obstáculos, reais ou não, que bl7oqueiam o acesso a esses bens.

Segundo MOURA (1992), as crianças e os adolescentes pobres vivenciam esta situação de conflito entre a fantasia e a realidade uma vez que estes são submetidos às pressões de consumo divulgados pela mídia. Sonham com um mundo que está fora de sua casa onde não precisam trabalhar e têm liberdade, enfim, onde todos os seus sonhos têm possibilidade quase garantida de se realizarem. BOUDON e BAURRICAUD (1993) colocam que há consumo global de um objeto quando este se torna visível para um grande número de prováveis consuinidores sendo função da publicidade garantir essa visibilidade e, com isso, desencadear o ato de compra.

No entanto, uma vez na rua e envolvidos em seu universo, os meninos e meninas se dão conta da fragilidade e instabilidade do sonho que os trouxera até ali e que, a sua concretização é complexa e está condicionada a experiências difíceis e precoces, podendo lhes custar, muiitas vezes, a própria vida. Assim, a impossibilidade de atingir o objetivo de consumo daqueles produtos que sentiam necessidade de possuir, pode levar os meninos a praticar atos ilícitos em busca do objeto, acompanhados ou não de atitudes agressivas.

\section{c) espaço de humilhação}

Em síntese, podemos observar através das entrevistas que os atores sociais de nossa pesquisa trazem a questão da humilhação como uma das faces que constróem as representações que têm da rua. Sentem-se humilhados em várias circunstâncias de suas vidas. Esta humilhação começa em casa, associada à falta de confiança, preconceito e desprezo pela própria família, onde muitas vezes são vítimas de violências físicas e psicológicas pelo pai, mãe, padrasto, madrasta ou tia:

“Na rua, ninguém ficava me de.sprezando que nem me desprezava na minha casa (E-I).

“Eu queria sair da rua para morar com a minha família. Aí até que eu consegui. Um dia eu fui com a minha família mas sempre vivendo no preconceito" (E-8).

Este sentimento se estende à rua no momento em que é preciso pedir (comida, roupa, dinheiro). Os meninos sentem-se humilhados pelos próprios colegas do grupo, pelas pessoas que passain pela rua, quando apanham da policia ou dos meninos com os quais convivem nas ruas, por não terem um lugar fixo para viver, para dormir, para se aquecerem nos dias de frio.

“Agora o ruim mesmo é ser humilhado pelas pessoas, né? As pessoas passam assim ficam vingando a gente e tal, por causa, a gente estava passando assim, passava uma pessoa, reconhece nós, e fala Ah..., porque olha lá, porque olha lá, esse cara é isso, e tal... é isso, e tal, é ladrão e tal e tudo mais, né e sempre assim, né... ser desprezado da.s pessoas, ser xingado, ser mal visto pela popula,cão, né? “(E-4).

Em suas falas, está implícito a huinilhação de viver na rua e de nao terem outra opção. Até mesmo ao ter de voltar para casa sentem-se humilhados pois significaria a derrota de não terem conseguido vencer na(a) rua:

"A rua se encaixa no lado ruim mas, eu não tenho nada que eu gostavu na rua prá falar sincero, mas, mas só que na situação que a gente vivia naquele tempo que a gente tinha, era obrigatório..." (E-3).

Em nosso entendimento, um dos possíveis significados que os meninos trazem para esta categoria, passa pela questão do próprio rótulo que a eles se impõe, isto é, são “'meninos de rua”. Assim, uma vez "menino de rua”, carregará consigo outras denominações que refletem a degradação social, o preconceito, a humilhação, o desprezo, a omissão, a discriminação e o descaso tanto do Estado quanto da sociedade de um modo geral e da própria fainilia do menino.

O Estatuto da Criança e do Adolescente (BRASIL, 1991), que passou a vigorar a partir de 1990, trouxe à sociedade brasileira um modo diferente de perceber a criança e o adolescente. Nesse sentido, observamos que vários segmentos da sociedade estão comprometidos com a questão da criança e do adolescente em situação de risco social no sentido de encontrar alternativas e propostas para a melhoria da qualidade de vida. No entanto, a criança pobre, com vínculos rompidos com a família e que anda pelas ruas cheirando cola, suja, maltrapilha, descalça e pedindo dinheiro ou comida, traz a resposta imediata à sociedade que esta é a caracterização básica do "menino de rua” e passa a temê-lo, repudiá-lo, desprezá-lo. Não leva em consideração que por trás daquele menino existe uma história de vida muitas vezes amarga de abandono, violência doméstica e pobreza que o leva a encontrar na rua e na cola de sapateiro, na mendicância sua única possibilidade de sobrevivência. 


\section{CONSIDERAÇÕES FINAIS}

De um modo geral, este estudo revelou que as representações sociais acerca de casa e rua, para o grupo de meninos entrevistados, são construídas a partir de elementos contraditórios.

Na Casa Abrigo, por meio de seu espaço físico e também dos profissionais que ali trabalhavam e dos meninos que a habitavam, desenrolavam-se situações que traduzem a representação de Casa pois ali se desenrola a trama das relações entre os meninos e os educadores e, também entre os próprios meninos. No entanto, representa um espaço de fragilidade nessas relações considerando que a Casa Abrigo supria em parte os vínculos familiares rompidos mas também significava a possibilidade de resgate de suas ligações parentais através da busca intensiva realizada pelos profissionais da Casa Abrigo. Quanto à rua, ao mesmo tempo em que significa algo de bom em suas vidas, pela falsa liberdade, também são marcantes os aspectos negativos presentes naquele espaço. Em outras palavras, a rua constitui-se em um cenário onde se passa a história desses meninos significando um espaço de liberdade e, ao mesmo tempo, de restrição.

Neste universo, pensar ações em saúde para que possamos contemplar meninos e meninas que vivem e/ou trabalham na rua é uma tarefa bastante complexa. O que fazer frente a esse quadro de tal dramaticidade? Como promover saúde, em certos casos, sem que sejam asseguradas as condições mínimas de sobrevivência? Essas e outras questões trazem, para o campo da Saúde Pública, desafios a serem vencidos ou, pelo menos, discutidos.

A partir desta nossa pesquisa e com base em outros estudos, no campo da saúde, sobre o assunto, a exemplo de MINAYO (1993b) e GOMES (1996), fazemos a seguir considerações que, embora sejam finais, servem de ponto de partida para a discussão, tanto nos campos das políticas em saúde e da gerência dos serviços, como no âmbito da implementação de ações.

Dado à complexidade da problemática em que os meninos e as meninas vivem, não é possível pensarmos em ações isoladas da saúde. Precisamos atravessar diferentes campos disciplinares, bem como necessitamos de ações intersetoriais. Para isso, faz-se necessário que busquemos parcerias com diferentes instituições, a exemplo de Varas da Infância e da Adolescência, Conselhos Tutelares e Organizações Não-Governamentais.

Também acreditamos que, independentemente de conseguirmos ou não parcerias, faz-se necessário que qualquer ação voltada para os sujeitos aqui referidos deve ser precedida pela compreensão do fato de que existem meninos e meninas que vivem na rua. Tal compreensão nos levará a repensar a promoção da assistência para essa população que, certamente, deverá ser diferenciada daquela que é pensada para as crianças e os adolescentes que vivem em famílias que possuem um endereço. $\mathrm{O}$ estar na rua, por diferentes motivos, não só deve nos trazer conteúdos específicos para as ações em saúde como também deve nos apontar caminhos alternativos aos que, tradicionalmente, vêm sendo trilhados.

\section{AGRADECIMENTOS}

Os autores agradecem o apoio do Núcleo de Estudos e Pesquisas em Saúde integral da Faculdade de Enfermagem da Universidade Federal de Goiás e o financiamento parcial do CNPq para a realização da pesquisa.

\begin{abstract}
The aim of this study was to analyze the social representations concerning house and street of boys with life experience in the street. The research was developed in light of the social approach of qualitative research in the health area. As a methodological principle, the social representations were extracted from the speech of a group of boys sheltered in a public institution. The results were analyzed through the content analysis technique - thematic modality, and showed that the social representations of house and street are built based on contradictory elements, i.e., the house, represented by the shelter, provides part of the family bonds, and the street is considered, at the same time, a freedom space and a place of privations. The conclusion is that the elaboration of health programs for boys and girls who live and/or work in the street is quite a complex task, as it is not possible to think about isolated health actions. It is necessary to search for partnerships with different institutions.
\end{abstract}

Keywords: street children; social research; public health. 


\section{REFERÊNCIAS BIBLIOGRÁFICAS}

ABRINQ/CBMM/UNICEF/OFICINA DE IDEIAS. 10 medidas básicas para a infância brasileira. São Paulo: Fundação ABRINQ para os Direitos da Criança, 1994.

BARDIN, L. Análise de conteúdo. Lisboa: Persona, 1979.

BOUDON, R.; BAURRICAUD, F. Dicionário crítico de sociologia. São Paulo: Ática, 1993.

BRASIL. Estatuto da criança e do adolescente: Lei 8069/90. São Paulo: Atlas, 1991.

CARLINI COTRIN, B.; COTRIN, E. L. A. O consumo de solventes e outras drogas em crianças e adolescentes de baixa renda na cidade de São Paulo: Parte 1. Estudantes de primeiro e segundo graus da rede estadual de ensino. Rev. ABP-APAL, 9(2): 49-58, 1987a.

CARLINI COTRIN, B; COTRIN, E. L. A. O consumo de solventes e outras drogas em crianças e adolescentes de baixa renda na cidade de São Paulo: Parte 11. Meninos de rua e menores infratores. Rev. ABP-APAL, 9(2): 69-77, 1987b.

CHIZZOTTI, A. Pesquisa em ciencias humanas e sociais. São Paulo: Cortez, 1991.

CRUZ NETO, O. O trabalho de campo como descoberta e criação. In: MINAYO, M. C. S. (Org.). O limite da exclusão social: meninos e meninas de rua no Brasil. São Paulo/ Rio de Janeiro: Hucitec/ Abrasco, 1993. p. 51 -66.

DA MATTA, R. Casa \& rua: espaço, cidadania, mulhere morte no Brasil, $5^{a}$ ed. Rio de Janeiro: Rocco, 1997.

FENELON, G. M.; MARTINS, L. C. Ç.; DOMINCUES, M. H. M. S. Meninas de rua: uma vida em movimento. Goiania: CEGRAF / UFG, 1992.

GOIANIA. Prefeitura Municipal. Sociedade Cidadão 2000. Entre a casa e a rua: três pesquisas sobre a criança e o adolescente na região metropolitana de Goiânia (GO). Goiânia, 2002. CD-ROM.

GOMES, R. O corpo na rua e o corpo da $n \sim a$. a prostituição infantil feminina em questão. São Paulo: Unimarco, 1996.

GOMES, R. A análise dos dados na pesquisa qualitativa. In: MINAYO, M.C.S. (Org.). Pesquisa social: teoria, método e criatividade. Petrópolis: Vozes, 2000. p. 67-80.

HAGUETTE, M. T. F. Metodologia qualitativa na sociologia. Petrópolis: Vozes, 1992.

HERZLICH, C. A problemática da representação social e sua utilidade no campo da doença. Physis. Rev. Sd. Coletiva, 1(2): 23-36, 1991.
MEDEIROS, M.; FERRIANI, M. G. C. Programas de atenção às crianças e aos adolescentes em situação de rua: percepções de seus coordenadores. Rev. Bras. Cresc. Desenv. Humano, 5(1/2): 48-59, 1995.

MEDEIROS, M. Olhando a lua pelo mundo da rua: representações sociais da experiência de vida de meninos em situação de rua. Ribeirão Preto, 1999. [Tese de Doutorado - Escola de Enferrnagem de Ribeirão Preto da USP].

MEDEIROS, M.; FERRIANI, M. G. C.; MUNARI, D. B.; GOMES, R. A sexualidade para o adolescente em situação de rua em Goiânia. Rev. Latinoamer. Enf., 9(2): 35-41, 2001.

MELLO, S. L. Famílias das classes populares: tradição e mudança. Rev. Bras. Cresc. Desenv. Humano, 4(1): 21-27, 1994.

MINAYO, M. C. S. O desafio do conhecimento: pesquisa qualitativa em saúde. São Paulo/ Rio de Janeiro: Hucitec/Abrasco, 1993a.

MINAYO, M. C. S. (Org.). O limite da exclusão social: meninos e meninas de rua no Brasil. São Paulo / Rio de Janeiro: Hucitec / Abrasco, 1993b.

MINAYO, M. C. S. Violência social sob a perspectiva da Saúde Pública. Cadernos de Saúde Pública, 10 (Supl. 1): 07-18, 1994.

MINAYO, M. C. S. (Org.). Pesquisa social: teoria, método e criatividade. $17^{\mathrm{a}}$ ed. Petrópolis: Editora Vozes, 2000.

MOURA, W. A família contra a rua: uma análise psicossociológica da dinâmica familiar em condições de pobreza. In: FAUSTO, A.; CERVINI, R. O trahalho e a rua: crianças e adolescentes no Brasil urbano dos anos 80. São Paulo: Cortez Editora, 1992.

PRADO, A.A.; GOMES, R. A rua: institucionalização da exclusão social. In MINAYO, M.C.S. (Org.). O limite da exclusão social: meninos e meninas de rua no Brasil. São Paulo/Rio de Janeiro: Ed. Hucitec/ABRASCO, 1993.

SARTI, C. A. A continuidade entre casa e rua no mundo da criança. Rev. Bras. Cresc. Desen. Hum. 5(1 / 2): 39-47, 1995.

SILVA, J. F. S. Uma análise crítica sobre a visão de mundo dos meninos e meninas de rua da cidade de São Carlos. São Paulo, 1993. [Dissertação de Mestrado. Pontifícia Universidade Católica de São Paulo].

SOUZA, H.; PEREIRA, J. L. R O orçamento da criança. Folha de São Paulo. São Paulo, 2 de maio de 1995, Opinião, $1^{\circ}$ Cademo, p.3, 1995.

Recebido em 07/05/2002 Modificado em 13/08/2002 Aprovado em 14/()8/2002 